\title{
CRESCIMENTO E NUTRIÇÃO DA BRAQUIÁRIA EM FUNÇÃO DE FONTES DE FÓSFORO
}

\author{
Growth and nutrition of marandu-grass as a function of phosphorus sources
}

\author{
Sérgio Ely Valadão Gigante de Andrade Costa ${ }^{1}$, Antônio Eduardo Furtini Neto ${ }^{2}$, \\ Álvaro Vilela de Resende ${ }^{3}$, Tácio Oliveira da Silva ${ }^{4}$, Talles Renan da Silva ${ }^{5}$
}

\begin{abstract}
RESUMO
Avaliaram-se, em casa de vegetação, as contribuições de diferentes fontes de fósforo $(\mathrm{P})$ aplicadas em amostras de Latossolo

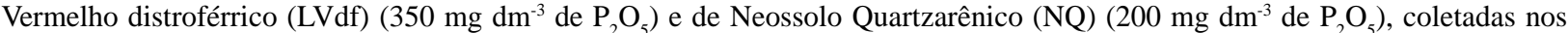
municípios de Lavras (MG) e Itutinga (MG), respectivamente, na produção de matéria seca, no teor e acúmulo de P na parte aérea e raiz da Brachiaria brizantha cv. Marandu. Também foi avaliado o índice de eficiência agronômica (IEA) das fontes. O experimento foi conduzido em um delineamento experimental inteiramente casualizado, em esquema fatorial $2 \times 4$ (dois solos e quatro fontes de fósforo (Superfosfato Triplo (ST), Fosfato Reativo de Arad (FR), Fosfato Natural de Araxá (FA), e uma mistura ST+FR - na relação (1:1), com quatro repetições. A dose de fósforo foi baseada no teor de $\mathrm{P}_{2} \mathrm{O}_{5}$ total das fontes. Para a produção total de matéria seca e o acúmulo total de P, as fontes de maior solubilidade, como o ST, FR e a mistura ST/FR foram mais eficientes, principalmente no primeiro, terceiro e quarto cortes no LVdf e em todos os cortes no NQ. O teor total de P na braquiária ao final do último corte foi maior quando se aplicaram as fonte FR e ST+FR para o LVdf e, ST e ST+FR para o NQ. As fontes de fósforo influenciaram o IEA nos dois solos, que foi maior para as fontes de maior solubilidade.
\end{abstract}

Termos para indexação: Índice de eficiência agronômica, matéria seca, acúmulo de fósforo.

\section{ABSTRACT}

The contribution of different phosphorus $(\mathrm{P})$ sources applied, under greenhouse conditions, in a clayey dystrophic Red Latosol - Oxisol (LVdf)(350 mg dm${ }^{-3}$ of $\mathrm{P}_{2} \mathrm{O}_{5}$ ) and a sandy Neosol - Entisol (NQ)(200 mg dm of $^{-3} \mathrm{O}_{5}$ ), collected from Lavras (MG) and Itutinga (MG) counties, respectively, on Braquiaria's (Brachiaria brizantha cv. Marandu) dry matter production, $\mathrm{P}$ content and accumulation were evaluated. Also agronomic efficiency index (AEI) of the P sources applied was measured. The experiment was carried out under a completely randomized $4 \times 2$ factorial, comparing four P sources (Triple superphosphate - TS, Arad reactive phosphate - RP, Araxá rock phosphate - AP, and a 1:1 ratio mixture TS+RP), with four replicates. The amount of P applied was based on the $\mathrm{P}_{2} \mathrm{O}_{5}$ content of each source. The forage was cultivated for four cuts. For total dry matter production and $\mathrm{P}$ accumulation, P sources of higher solubility, as TS, RP and TS+RP were more efficient, especially for the first, third and forth cuts in the LVdf soil and for all cuts for the NQ soil. By the last cut, Braquiaria's total P content was higher when RP and TS+RP sources were applied for the LVdf soil and TS and TS+RP for the NQ soil. The different P sources had influence on AEI on both soils, for the LVdf soil as for the NQ soil P sources of higher solubility (RP and TS+RP) presented higher AEI.

Index terms: Agronomic efficiency index, dry matter, phosphorus accumulation.

(Recebido em 3 de julho de 2006 e aprovado em 3 de maio de 2007)

\section{INTRODUÇÃO}

O fósforo $(\mathrm{P})$ é um nutriente essencial para todos os seres vivos. Na produção vegetal, em solos tropicais, o $\mathrm{P}$ é considerado o nutriente mais importante, apesar das necessidades das plantas serem relativamente pequenas quando comparadas com outros macronutrientes (ROSSI et al., 1999). No Brasil, cerca de $70 \%$ dos solos cultivados apresentam alguma limitação séria de fertilidade e o fósforo é o elemento cuja falta limita mais freqüentemente a produção das culturas nos solos ácidos tropicais (SANTOS, H. et al., 2002). Essa limitação deve-se ao fato de que, nos solos ácidos, o fósforo solúvel em água transforma-se em fosfato de ferro e fosfato de alumínio que se tornam não disponíveis às plantas (NAKAYAMA et al., 1998). A importância do $\mathrm{P}$ para a produtividade das

\footnotetext{
Engenheiro Agrônomo, Mestrando - Departamento de Ciência do Solo - Faculdade de Agronomia - Universidade Federal do Rio Grande do Sul/UFRGS Avenida Bento Gonçalves, 7712 - 91920-130 - Porto Alegre, RS - sergioelycosta@hotmail.com

${ }^{2}$ Engenheiro Agrônomo, Doutor, Professor Adjunto - Departamento de Ciência do Solo/DCS - Universidade Federal de Lavras/UFLA - Cx. P. 3037 37200-000 - Lavras, MG - afurtini@ufla.br

${ }^{3}$ Engenheiro Agrônomo, Doutor em Solos e Nutrição de Plantas, Pesquisador - Embrapa Cerrados/CPAC - Br 020, Km 18 - Cx. P. 08223 - $73310-970$ Planaltina, DF - alvaro@cpac.embrapa.br

${ }^{4}$ Engenheiro Agrônomo, Doutor em Ciência do Solo - Centro de Ciências Agrárias, Ambientais e Biológicas/CCAAB - Laboratório de Fertilidade do Solo Universidade Federal do Recôncavo da Bahia/UFRBA - Rua Rui Barbosa, s/n - 44380-000 - Cruz das Almas, BA - taccios@hotmail.com ${ }^{5}$ Engenheiro Agrônomo - Departamento de Ciência do Solo/DCS - Universidade Federal de Lavras/UFLA - Cx. P. 3037 - $37200-000$ - Lavras, MG tallesrenan@yahoo.com.br
} 
plantas decorre de sua participação nas estruturas e processos vitais para o desenvolvimento dos vegetais (MARSCHNER, 1995).

A complexa dinâmica do $\mathrm{P}$ nos solos tropicais é de grande importância e a principal causa da indisponibilidade do nutriente está ligada à reduzida eficiência de aproveitamento dos fertilizantes fosfatados (YOST et al., 1981). A incorporação de novas áreas à agropecuária brasileira, que apresentam alto dreno de fósforo e baixíssima disponibilidade do mesmo, tem feito com que a utilização dos fosfatos in natura seja um atrativo como fonte do nutriente para as plantas, uma vez que há uma disponibilidade gradual de $\mathrm{P}$ e um favorecimento do aumento da quantidade do nutriente ao longo do tempo (NOVAIS \& SMYTH, 1999).

A eficiência da adubação fosfatada é influenciada por vários fatores, dentre os quais, o tipo de solo e a fonte de $\mathrm{P}$ utilizada. A demanda de $\mathrm{P}$ nas adubações depende da textura do solo, uma vez que o tamponamento, diretamente relacionado ao teor de argila, vai modular a fração de P que permanecerá disponível para a planta. Assim, comparativamente com os solos arenosos, os solos argilosos requerem quantidades mais elevadas de fosfato para atender à demanda de uma dada cultura (NOVAIS \& SMYTH, 1999; SOUSA et al., 2004). Novais \& Smyth (1999) relataram que solos com alta CTC, baixa concentração de P-solução, baixa ou nula concentração de Al trocável favoreceriam a maior solubilização dos fosfatos naturais de baixa reatividade. Goedert \& Lobato (1984) complementaram que o baixo teor de cálcio trocável nos solos do cerrado é uma condição favorável à solubilização de fosfatos naturais apatíticos.

A maior parte das áreas com pastagens encontrase degradadas ou em processo de degradação em conseqüência de inúmeros fatores, sendo o principal, o manejo inadequado da fertilidade dos solos. Assim esta torna-se crucial para a recuperação destas áreas, tendo o fósforo recebido uma atenção especial em condições tropicais (DELISTOIANOV et al., 1992).

Neste trabalho, objetivou-se avaliar a resposta do braquiarão [Brachiaria brizantha (Hochst. ex. A. Rich.) Stapf. cv. Marandu] a diferentes fontes de fósforo, em dois solos distintos característicos da região do cerrado.

\section{MATERIAL E MÉTODOS}

O experimento foi conduzido em casa de vegetação do Departamento de Ciência do Solo, na Universidade Federal de Lavras, Lavras (MG). As amostras de solos, foram coletadas na camada de $0-20 \mathrm{~cm}$ de profundidade em um Latossolo Vermelho distroférrico (LVdf), de textura argilosa e em um Neossolo Quartzarênico (NQ), textura arenosa (EMBRAPA, 1999), localizados, respectivamente nos municípios de Lavras (MG) e Itutinga (MG). Salientase a baixa disponibilidade de fósforo extraído pela resina de troca iônica, 1,8 e 3,1 $\mathrm{mg} \mathrm{dm}^{-3}$, no NQ e LVdf, respectivamente (RAIJ et al., 1996).

As amostras de solo foram destorroadas e passadas em peneira de $4 \mathrm{~mm}$ de abertura de malha e secas ao ar e subamostras foram passadas em peneira de $2 \mathrm{~mm}$ de abertura de malha (TFSA) para as determinações químicas e físicas. Amostras dos solos foram acondicionadas em vasos com capacidade de $3 \mathrm{dm}^{3}$ até a aplicação dos tratamentos.

Após a aplicação de calcário dolomítico para elevar a saturação por bases a $55 \%$, as amostras foram incubadas por 50 dias, mantendo-se a umidade em $60 \%$ do volume total de poros (FREIRE et al., 1980). Após a incubação, procedeu-se à aplicação das fontes de fósforo sendo que a quantidade de cada fonte foi calculada com base no seu teor de $\mathrm{P}_{2} \mathrm{O}_{5}$ total. As doses de $\mathrm{P}$ aplicadas corresponderam a $350 \mathrm{mg} \mathrm{dm}^{-3} \mathrm{de}_{2} \mathrm{O}_{5}$ para o Latossolo Vermelho distroférrico (LVdf) e $200 \mathrm{mg} \mathrm{dm}^{-3} \mathrm{P}_{2} \mathrm{O}_{5}$ para o Neossolo Quartzarênico (NQ). Concomitantemente à aplicação de $\mathrm{P}$, a adubação básica foi realizada com os demais nutrientes através de fontes de sais pró-análise, sendo que as doses de macro e micronutrientes consistiram de: $100 \mathrm{mg}$ de $\mathrm{N} ; 100 \mathrm{mg}$ de $\mathrm{K} ; 40 \mathrm{mg}$ de $\mathrm{S} ; 5$ $\mathrm{mg}$ de $\mathrm{Zn} ; 1,5 \mathrm{mg}$ de $\mathrm{Cu}$; 3,6 mg de $\mathrm{Mn}$; 0,8 mg de B; 0,15 mg de Mo por $\mathrm{dm}^{3}$, aplicados em solução e misturados aos vasos individualmente para melhor homogeneização. As adubações complementares com $\mathrm{N}$ e $\mathrm{K}$ foram diferenciadas de acordo com o crescimento da forragem em cada tratamento.

$\mathrm{O}$ delineamento experimental utilizado foi o inteiramente casualizado em um arranjo fatorial $4 \times 2$, constituído por quatro fontes de $\mathrm{P}$ correspondentes ao superfosfato triplo (ST) $-46,1 \%$ de $\mathrm{P}_{2} \mathrm{O}_{5}$ total; fosfato reativo de $\mathrm{Arad}(\mathrm{FR})-33,1 \%$ de $\mathrm{P}_{2} \mathrm{O}_{5}$ total; fosfato natural de Araxá (FA) - 22,71\% de $\mathrm{P}_{2} \mathrm{O}_{5}$ total; uma mistura ST+FR na relação 1:1, dois solos, Latossolo Vermelho distroférrico (LVdf) e o Neossolo Quartzarênico(NQ), com quatro repetições, num total de 32 unidades experimentais. Após a aplicação das fontes de fósforo, da adubação básica, e de um período de 15 dias de incubação das amostras de solo em casa de vegetação, o material de solo foi avaliado de acordo com metodologia descrita em Embrapa (1999) (Tabela 1). Cabe ressaltar, que somente a fonte FA no LVdf, não atingiu o nível crítico exigido pela forrageira (CORRÊA, 1993). 
Tabela 1 - Atributos dos solos Neossolo Quartzarênico e Latossolo Vermelho distroférrico, após realização da adubação básica e aplicação das fontes de $\mathrm{P}$, respectivamente.

\begin{tabular}{|c|c|c|c|c|c|c|c|c|}
\hline \multirow[t]{2}{*}{ Características } & \multicolumn{4}{|c|}{-----------------NQ--------------- } & \multicolumn{4}{|c|}{---------------LVdf------------- } \\
\hline & ${ }^{1} \mathrm{ST}$ & FR & FA & ST/FR & ST & FR & FA & $\overline{\mathrm{ST} / \mathrm{FR}}$ \\
\hline $\mathrm{pH}\left(\mathrm{H}_{2} \mathrm{O}\right)$ & 5,3 & 5,2 & 5,2 & 5,3 & 6,1 & 6,2 & 6,0 & 6,2 \\
\hline $\mathrm{P}$ - Resina $\left(\mathrm{mg} \mathrm{dm}^{-3}\right)$ & 108,7 & 30,5 & 10,8 & 134,2 & 121,1 & 69,1 & 6,3 & 77,5 \\
\hline P -Remanescente ( $\left.\mathrm{mg} \mathrm{L}^{-1}\right)$ & 37,7 & 34,7 & 36,7 & 35,7 & 2,2 & 2,2 & 1,8 & 1,5 \\
\hline $\mathrm{K} \quad\left(\mathrm{mg} \mathrm{dm} \mathrm{m}^{-3}\right)$ & 90 & 66 & 59 & 66 & 84 & 84 & 78 & 97 \\
\hline $\mathrm{Ca}^{2+}\left(\mathrm{cmol}_{\mathrm{c}} \mathrm{dm}^{-3}\right)$ & 1,3 & 1,4 & 1,4 & 1,2 & 1,1 & 1,1 & 1,2 & 1,2 \\
\hline $\mathrm{Mg}^{2+}\left(\mathrm{cmol}_{\mathrm{c}} \mathrm{dm}^{-3}\right)$ & 0,7 & 0,7 & 0,7 & 0,9 & 0,5 & 0,4 & 0,4 & 0,4 \\
\hline $\mathrm{Al}^{3+} \quad\left(\mathrm{cmol}_{\mathrm{c}} \mathrm{dm}^{-3}\right)$ & 0,3 & 0,3 & 0,3 & 0,3 & 0 & 0 & 0 & 0 \\
\hline $\mathrm{H}+\mathrm{Al}$ Acidez potencial $\left(\mathrm{cmol}_{\mathrm{c}} \mathrm{dm}^{-3}\right)$ & 2,3 & 2,3 & 2,6 & 2,3 & 1,7 & 1,5 & 1,7 & 1,7 \\
\hline SB Soma de bases $\left(\mathrm{cmol}_{\mathrm{c}} \mathrm{dm}^{-3}\right)$ & 2,2 & 2,3 & 2,3 & 2,3 & 1,8 & 1,7 & 1,7 & 1,7 \\
\hline t- CTC efetiva $\quad\left(\mathrm{cmol}_{\mathrm{c}} \mathrm{dm}^{-3}\right)$ & 2,5 & 2,6 & 2,5 & 2,6 & 1,8 & 1,7 & 1,7 & 1,7 \\
\hline T- CTC a pH 7,0 $\left(\mathrm{cmol}_{\mathrm{c}} \mathrm{dm}^{-3}\right)$ & 4,5 & 4,6 & 4,8 & 4,6 & 3,5 & 3,2 & 3,4 & 3,4 \\
\hline V- Saturação por bases (\%) & 49,2 & 49,7 & 46,4 & 49,7 & 51,6 & 53,3 & 50,0 & 49,3 \\
\hline Matéria orgânica $\left(\mathrm{g} \mathrm{kg}^{-1}\right)$ & 10 & 12 & 11 & 15 & 25 & 25 & 25 & 25 \\
\hline m- Saturação por alumínio(\%) & 12 & 12 & 12 & 12 & 0 & 0 & 0 & 0 \\
\hline
\end{tabular}

${ }^{1} \mathrm{ST}=$ Superfosfato Triplo, FA = Fosfato de Araxá, FR = Fosfato Reativo de Arad, ST/FR= mistura 1:1 superfosfato triplo e fosfato reativo de Arad.

Em seguida, procedeu-se a semeadura da Brachiaria brizantha cv. Marandu, com posterior desbaste, deixando-se quatro plantas por vaso. Aos 48 dias após a semeadura, foi efetuado o primeiro corte da parte aérea da forrageira a $2 \mathrm{~cm}$ do solo. Realizaram-se quatro cortes, no período de 02/12/2004 a 23/03/2005, com intervalos médios de 48 dias. Após cada corte, a fitomassa da forrageira foi seca em estufa de circulação forçada a $65^{\circ} \mathrm{C}$ até massa constante para a obtenção da produção da massa da matéria seca da parte aérea (MSPA). Amostras de MSPA foram analisadas quanto aos teores de nutrientes, conforme metodologias descritas por Malavolta et al. (1997). As raízes foram recuperadas, lavadas com água deionizada e também seca em estufa de circulação forçada a $65^{\circ} \mathrm{C}$. Após o último corte, antes do florescimento, as plantas foram colhidas, separandoas em parte aérea e raízes.

Ao término do último corte, considerando os resultados acumulados dos quatro cortes, foi determinado o conteúdo de fósforo (CP), através do produto da matéria seca pelo teor de $\mathrm{P}$ nos respectivos componentes das plantas. Calculou-se também o Índice de Eficiência Agronômica das (IEA) para a MSPA do capim-marandu em todos os cortes conforme sugerido por Novais \&
Smyth (1999), tomando-se o ST como $100 \%$ a partir da fórmula:

IEA $=($ Prod. fonte testada $)$ - (Prod. test.). 100/ (Prod Superfosfato triplo) - (Prod. test.)

As variáveis avaliadas foram submetidas à análise de variância e as médias comparadas através do teste Tukey a $5 \%$ de probabilidade, com o uso do programa estatístico SISVAR.

\section{RESULTADOS E DISCUSSÃO}

\section{Produção de matéria seca}

A aplicação das fontes de maior solubilidade de $\mathrm{P}$ incrementou a produção de matéria seca da braquiária nos dois solos (Tabela 2). Independente da solubilidade dos fosfatos, as maiores produções de fitomassa da parte aérea e raiz foram alcançadas no NQ, exceção para o fosfato de Araxá (FA), onde a produção de raiz foi maior no LVdf (Tabela 2). Ao final do primeiro corte, na presença da fonte de maior solubilidade (ST) e da mistura ST + FR, a braquiária cultivada no LVdf respondeu com maior produção de biomassa da parte aérea, sendo o mesmo comportamento observado nas raízes ao final do cultivo. A aplicação de 
Fosfato de Araxá (FA) promoveu uma menor produção de matéria seca, diferindo significativamente das demais fontes (Tabela 2). A partir do segundo corte da forrageira, o FR proporcionou uma maior produção de matéria seca da forrageira em ambos os solos, no entanto, no solo mais argiloso (LVdf) este comportamento ficou mais evidente. No terceiro corte, no LVdf, as fontes ST e ST+FR, não apresentaram diferença significativa com relação ao tratamento com o FR. Em estudo dos efeitos da adubação verde associada a fosfato de rocha na cultura do milho em um Argissolo Vermelho-Escuro distrófico, Araújo \& Almeida (1993), reportaram que a produção de matéria seca para esta cultura foi maior quando se aplicou o superfosfato triplo.

Em relação ao NQ, a maior produção de matéria seca da parte aérea nos primeiros três cortes foi observada nos tratamentos em que estavam presentes as fontes de maior solubilidade (ST e ST + FR), comportamento semelhante ao observado no LVdf, embora com menores produções neste último (Tabela 2). No quarto corte, a menor produção de matéria seca foi observada quando da aplicação de FA. No NQ, a produção total de matéria seca seguiu comportamento semelhante ao dos tratamentos observado nos demais cortes, ou seja, $\mathrm{ST}=\mathrm{ST}+\mathrm{FR}>\mathrm{FR}>\mathrm{FA}$ (Tabela 2). Esta resposta reflete o baixo tamponamento presente em solos de textura mais arenosa, que promove uma maior disponibilização do $\mathrm{P}$ e solubilização mais lenta de fontes de menor reatividade (FR e FA). Delistoianov et al. (1992), avaliando diferentes fontes de fósforo associadas ao gesso sobre a produtividade da Digitaria decumbens Steat. e a participação de algumas espécies de leguminosas forrageiras, em um Latossolo Vermelho-Escuro, observaram que, no quarto ano de cultivo, a produção de matéria seca total foi maior para o fosfato de alvorada que diferiu significativamente do superfosfato triplo. Cabe ressaltar o efeito da diferença na disponibilidade de $\mathrm{P}$, em relação às fontes utilizadas, entre os dois solos sobre o crescimento radicular da braquiária (Tabela 2 ).

No NQ, não foi observada diferença na relação MSPA/MSR em função das fontes de P. Todavia para esse solo, os valores de MSPA/MSR foram mais elevados em comparação aos obtidos no LVdf. Neste contexto, verificase que, de uma forma geral, os valores de MSPA no NQ foram superiores ao LVdf, promovendo esta alteração nos valores da relação MSPA/MSR. Em relação às raízes, em conseqüência das características físicas e menor tamponamento do NQ relativamente ao LVdf, a braquiária cultivada neste solo apresentou maiores valores de MSR. Rao et al. (1996), destacaram que em relação à parte aérea, o crescimento das raízes é menos limitado na condição de deficiência de $\mathrm{P}$, sendo preponderante em solos mais argilosos, acarretando um típico decréscimo na razão MSPA/MSR. Mesquita et al. (2004), em um ensaio com Brachiaria brizantha cultivada em Latossolo Vermelho distroférrico, Neossolo Quartzarênico e Latossolo Vermelho- Amarelo distroférrico e com 4 doses de P, verificaram que a aplicação de $\mathrm{P}$ favoreceu mais a produção da parte aérea que a das raízes em todos os solos.

No LVdf, em condições de maior tamponamento, a relação MSPA/MSR para as fontes de menor solubilidade (FR e FA) foi maior em relação às fontes de maior solubilidade (ST e ST+FR). Este comportamento pode ser explicado pelos maiores valores de MSR, para as fontes de maior solubilidade (ST e ST + FR) em relação às de menor solubilidade (FR e FA) (Tabela 2.). O P prontamente disponível para a planta, oriundo de fontes mais solúveis, promoveu um maior crescimento radicular no estabelecimento da forrageira. Segundo Santos, I. et al. (2002), o fósforo desempenha papel importante no crescimento do sistema radicular, bem como no perfilhamento das gramíneas, proporcionando uma maior produtividade. Ressalta-se também, a estreita diferença nos valores de MSPA (total) entre as fontes de P, uma vez que foi observado neste solo uma equiparação do efeito das fontes sobre a produção de MSPA ao longo dos cortes (Tabela 2).

\section{Teor e acúmulo de $P$ na planta}

O teor de $\mathrm{P}$ na braquiária foi influenciado significativamente pelas fontes de P (Tabela 3 ). A forrageira, em todos os cortes, apresentou teores acima dos considerados críticos para todas as fontes, em ambos os solos (CORRÊA, 1993). A solubilidade das fontes, fator determinante nos valores de MSPA (Tabela 2), também influenciou nos teores e acúmulo de $\mathrm{P}$ nos dois solos uma vez que, de maneira geral, as fontes mais solúveis proporcionaram maiores teores de $\mathrm{P}$, maior MSPA e, conseqüentemente, maior acúmulo de $\mathrm{P}$. No entanto, no solo mais tamponado ( $\mathrm{LVdf}$ ), a solubilidade das fontes concorreu para um comportamento distinto. Neste solo, as plantas submetidas à fonte menos solúvel (FA) apresentaram menores teores de $\mathrm{P}$, menor MSPA e, consequentemente, menor acúmulo de $\mathrm{P}$, enquanto que aquelas fertilizadas com FR tenderam a equiparar-se àquelas fertilizadas com fontes mais solúveis ao longo dos cortes. Horowitz \& Meurer (2003), verificaram que, em geral, a eficiência agronômica dos fosfatos reativos é similar a dos fosfatos de alta solubilidade no primeiro ano e maior quando considerados os seus efeitos residuais. 
Tabela 2 - Matéria seca da parte aérea (MSPA) da Brachiaria brizanhta cv. Marandu em quatro cortes, ao final dos cortes (Total) e relação matéria seca de parte aérea e raízes (MSPA/MSR), em função de diferentes fontes de fósforo.

\begin{tabular}{|c|c|c|c|c|c|c|c|}
\hline Tratamento $^{1}$ & $1^{\circ}$ corte & $2^{\circ}$ corte & $3^{\circ}$ corte & $4^{\circ}$ corte & Total & MSPA/MSR & Raízes $^{2}$ \\
\hline \multicolumn{8}{|c|}{ 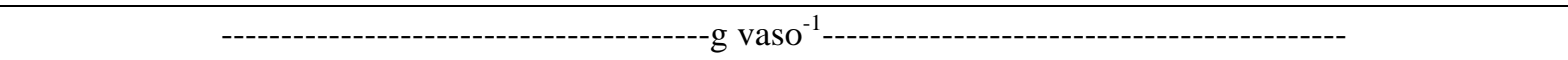 } \\
\hline \multicolumn{8}{|c|}{ Latossolo Vermelho distroférrico (LVdf) } \\
\hline ST & $7,97 \mathrm{a}$ & $15,86 \mathrm{a}$ & $13,08 \mathrm{ab}$ & $12,32 \mathrm{~b}$ & $49,24 \mathrm{a}$ & $1,66 \mathrm{~b}$ & $30,19 \mathrm{a}$ \\
\hline FA & $2,16 \mathrm{c}$ & $14,52 \mathrm{a}$ & $11,26 \mathrm{~b}$ & $12,72 \mathrm{ab}$ & $40,66 \mathrm{~b}$ & $2,58 \mathrm{a}$ & $16,65 \mathrm{~b}$ \\
\hline FR & $4,98 \mathrm{~b}$ & $18,56 \mathrm{a}$ & $14,37 \mathrm{a}$ & $14,12 \mathrm{a}$ & $52,03 \mathrm{a}$ & $2,03 \mathrm{ab}$ & $26,06 \mathrm{ab}$ \\
\hline $\mathrm{ST}+\mathrm{FR}$ & $8,04 \mathrm{a}$ & $15,55 \mathrm{a}$ & 13,65 a & $14,27 \mathrm{a}$ & 51,52 a & $1,59 \mathrm{~b}$ & $33,87 \mathrm{a}$ \\
\hline \multicolumn{8}{|c|}{ Neossolo Quartzarênico (NQ) } \\
\hline ST & $24,44 \mathrm{a}$ & $29,55 \mathrm{a}$ & $19,24 \mathrm{a}$ & $19,04 \mathrm{a}$ & $92,28 \mathrm{a}$ & $2,12 \mathrm{a}$ & $43,68 \mathrm{a}$ \\
\hline FA & $1,92 \mathrm{c}$ & $13,69 \mathrm{c}$ & $10,14 \mathrm{c}$ & $14,64 \mathrm{~b}$ & $40,39 \mathrm{c}$ & $1,97 \mathrm{a}$ & $21,01 \mathrm{~b}$ \\
\hline FR & $8,98 \mathrm{~b}$ & $20,64 \mathrm{~b}$ & $13,03 \mathrm{~b}$ & $18,38 \mathrm{a}$ & $61,05 \mathrm{~b}$ & $2,37 \mathrm{a}$ & $25,98 \mathrm{~b}$ \\
\hline $\mathrm{ST}+\mathrm{FR}$ & $24,26 \mathrm{a}$ & $26,99 a$ & $17,41 \mathrm{a}$ & $18,70 \mathrm{a}$ & $87,37 \mathrm{a}$ & $2,18 \mathrm{a}$ & $40,77 \mathrm{a}$ \\
\hline
\end{tabular}

${ }^{1} \mathrm{ST}=$ Superfosfato Triplo, FA = Fosfato de Araxá, FR = Fosfato Reativo de Arad $;{ }^{2}$ raízes coletadas ao final do último corte. Médias na coluna, seguidas da mesma letra não diferem entre si pelo teste Tukey a 5\% de probabilidade.

No LVdf, constatam-se teores maiores de P na braquiária submetida ao FA e FR, no primeiro corte, $\mathrm{ST}+\mathrm{FR}$ e FR, no segundo corte, ST+FR, ST e FR, no terceiro corte e ST+FR e ST, no quarto corte. Estes resultados diferem dos encontrados por Delistoianov et al. (1992), que verificaram teores maiores de P na parte aérea da Digitaria decumbens Stent. para o superfosfato triplo (ST) no primeiro ano. Os mesmos autores encontraram resultados coerentes com os do último corte ( $4^{\circ}$ corte) do presente estudo (Tabela 3), apenas para o teor de P na parte aérea da gramínea, quando se utilizou o superfosfato triplo, onde o mesmo superou os fosfatos de Araxá, Patos e Alvorada em relação ao teor de $\mathrm{P}$.

No LVdf, para o FA, os teores de P na fitomassa da parte aérea da $B$. brizantha, de modo geral, decresceram do primeiro para o último corte, possivelmente causado pelo efeito de diluição proporcionado pelo maior crescimento a partir do $2^{\circ}$ corte da gramínea (Tabela 2 ). Este comportamento corrobora com o verificado por Faquin et al. (1997), quando estudaram o efeito da aplicação de calcário e fontes de P na nutrição do braquiarão em um latossolo.

As plantas fertilizadas com ST, ainda no LVdf, quando comparadas àquelas submetidas ao FA, apresentaram maiores teores de $\mathrm{P}$ na biomassa da parte aérea da braquiária a partir do $3^{\circ}$ corte. $\mathrm{O}$ maior teor foi verificado para a fonte $S T$, a qual apresentou diferença significativa em relação às demais (Tabela 3).
No NQ, de modo geral, em todos os cortes, a fonte de maior solubilidade (ST) proporcionou o maior teor de $\mathrm{P}$ para o capim-Marandu (Tabela 3), ocasionando uma maior produção de matéria seca (Tabela 2). Os teores maiores de $\mathrm{P}$ na braquiária para os fosfatos naturais (FA e FR) foram observados quando cultivada no LVdf, em conseqüência, certamente, do efeito de concentração, uma vez que neste solo observou-se menor produção de MSPA. Novais \& Smyth (1999) relataram que a dissolução do fosfato natural deverá ser mais intensa em solos com maior CTC e, particularmente, com maiores teores de matéria orgânica. Ainda no NQ, não foi observado um efeito das fontes de $\mathrm{P}$ aplicadas no teor de $\mathrm{P}$ nas raízes (Tabela 3 ).

Os fosfatos utilizados apresentaram efeito positivo sobre o acúmulo de $\mathrm{P}$ na braquiária, para ambos os solos (Figuras 1 e 2). No LVdf, a braquiáira no primeiro corte apresentou maior acúmulo de $\mathrm{P}$ nos tratamentos com a presença do ST e FR, no segundo, com os tratamentos FR e ST+FR, e no terceiro e quarto cortes com ST+FR e FR. Em relação ao conteúdo total de $\mathrm{P}$ (CTP), o maior acúmulo de P na gramínea foi observado nos tratamentos ST+FR e FR, seguido pelo tratamento ST e FA (Figura 1).

No NQ, com textura mais arenosa, menor poder tampão, baixa capacidade de fixação de fósforo e, consequentemente, valores mais elevados de MSPA, podese observar um maior acúmulo de $\mathrm{P}$ pela braquiária, principalmente nas fontes de maior solubilidade (Figura 2). A baixa capacidade de fixação de $\mathrm{P}$ dos solos arenosos 
Tabela 3 - Teor de fósforo na fitomassa da parte aérea de cada corte, e das raízes ao término do último corte, da Brachiaria brizantha cv. Marandu, em função das diferentes fontes de fósforo.

\begin{tabular}{lccccc}
\hline Tratamento $^{1}$ & $1^{\circ}$ corte & $2^{\circ}$ corte & $3^{\circ}$ corte & $4^{\circ}$ corte & Raiz \\
\hline \multicolumn{5}{c}{ Latossolo Vermelo distroférrico (LVdf) } \\
\hline ST & $0,-----$ & $0,78 \mathrm{a}$ \\
FA & $1,22 \mathrm{a}$ & $0,96 \mathrm{bc}$ & $0,89 \mathrm{c}$ & $0,84 \mathrm{c}$ & $0,38 \mathrm{c}$ \\
FR & $0,88 \mathrm{~b}$ & $1,12 \mathrm{ab}$ & $1,03 \mathrm{~b}$ & $1,22 \mathrm{~b}$ & $0,52 \mathrm{~b}$ \\
ST+FR & $0,75 \mathrm{~b}$ & $1,19 \mathrm{a}$ & $1,31 \mathrm{a}$ & $1,41 \mathrm{a}$ & $0,57 \mathrm{~b}$ \\
\hline \multicolumn{7}{c}{ Neossolo Quartzrênico (NQ) } \\
\hline ST & $1,00 \mathrm{a}$ & $1,08 \mathrm{a}$ & $0,86 \mathrm{a}$ & $0,98 \mathrm{a}$ & $0,37 \mathrm{a}$ \\
FA & $0,77 \mathrm{~b}$ & $0,76 \mathrm{~b}$ & $0,69 \mathrm{~b}$ & $0,73 \mathrm{~b}$ & $0,43 \mathrm{a}$ \\
FR & $0,55 \mathrm{c}$ & $0,79 \mathrm{~b}$ & $0,78 \mathrm{ab}$ & $0,83 \mathrm{~b}$ & $0,43 \mathrm{a}$ \\
ST+FR & $0,75 \mathrm{bc}$ & $0,77 \mathrm{~b}$ & $0,81 \mathrm{ab}$ & $0,85 \mathrm{~b}$ & $0,36 \mathrm{a}$ \\
\hline
\end{tabular}

${ }^{1} \mathrm{ST}=$ Superfosfato Triplo, FA = Fosfato de Araxá, FR = Fosfato Reativo de Arad; ${ }^{2}$ Médias na coluna, seguidas da mesma letra não diferem entre si pelo teste Tukey a $5 \%$ de probabilidade.

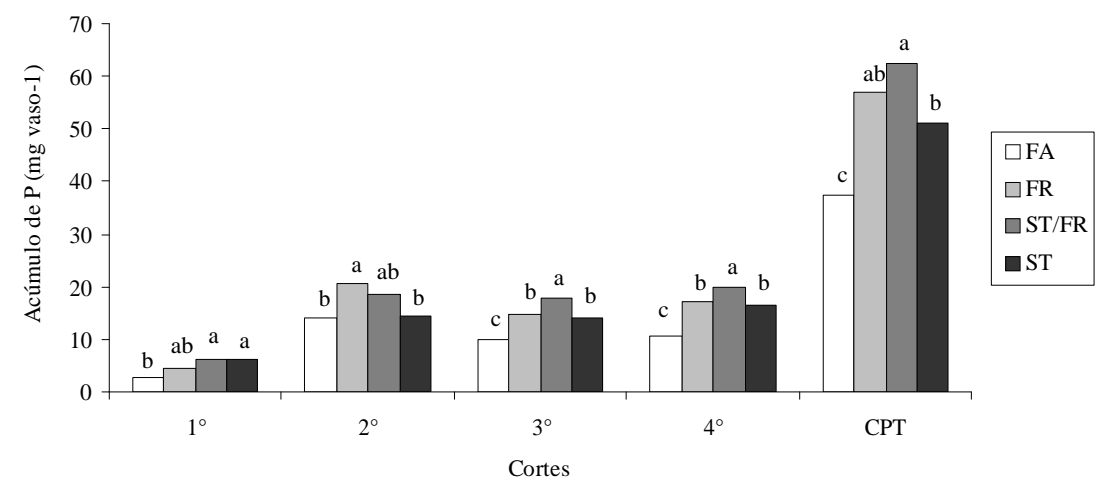

Médias seguidas pelas mesmas letras nas colunas, não diferem entre si ao nível de 5\% pelo teste Tukey.

Figura 1 - Acúmulo de P durante os cortes e total (CTP) da Bracharia brizantha submetida a diferentes fontes de P cultivada em um Latossolo Vermelho distroférrico.

promove uma maior disponibilização do P oriundo do ST, o que ficou evidente nas respostas da gramínea a esta fonte. Neste contexto, cabe ressaltar que o menor dreno de $\mathrm{P}$ em solos mais arenosos, acarreta uma menor eficiência das fontes de menor solubilidade (FR e FA) nestes solos, quando comparado a solos mais argilosos.

\section{Eficiência Agronômica de P - IEA}

As fontes de fósforo influenciaram o IEA nos dois solos (Tabela 4), sendo que as fontes de maior solubilidade (FR e ST+FR) apresentaram maior IEA para a produção de fitomassa em todos os cortes, confirmando a validade deste índice como indicativo da eficiência da adubação fosfatada (Tabela 4). Comparando-se a produção de MSPA no NQ e LVdf, com o ST, verificou-se que o incremento na produção de fitomassa da parte aérea no NQ variou de 147 a $307 \%$, embora no LVdf a dose de P aplicada tenha sido maior. Já, para a fonte de menor solubilidade, o FA, essa variação entre os solos foi menor, variando de 89 a $115 \%$. Essa comparação para o fosfato reativo de Arad (FR) variou de 91 a $180 \%$. Para os fosfatos de média e baixa solubilidade, os rendimentos de matéria seca foram aumentados com o tempo, sendo verificados melhores rendimentos no último corte da forrageira (Tabela 4), comportamento expresso 


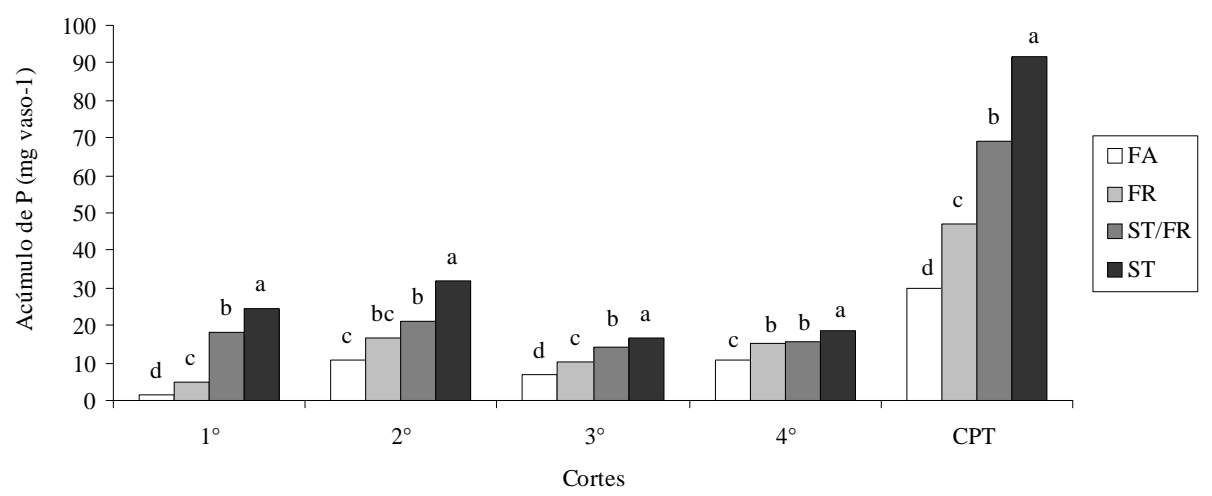

Médias seguidas pelas mesmas letras nas colunas, não diferem entre si ao nível de 5\% pelo teste Tukey.

Figura 2 - Acúmulo de P durante os cortes e total (CTP) da Bracharia brizantha submetida a diferentes fontes de P e cultivada em um Neossolo Quartzarênico.

Tabela 4 - Eficiência Agronômica das fontes de P em relação ao superfosfato triplo (ST) na produção de matéria seca da parte aérea da Brachiaria brizantha cv. Marandu, cultivado em solos distintos.

\begin{tabular}{|c|c|c|c|c|c|}
\hline Tratamentos ${ }^{1}$ & $1^{\circ}$ corte & $2^{\circ}$ corte & $3^{\circ}$ corte & $4^{\circ}$ corte & Total \\
\hline \multicolumn{6}{|c|}{ - } \\
\hline \multicolumn{6}{|c|}{ Latossolo Vermelho distroférrico (LVdf) } \\
\hline ST & 100 & 100 & 100 & 100 & 100 \\
\hline FA & 27 & 91 & 86 & 103 & 83 \\
\hline FR & 62 & 117 & 109 & 115 & 106 \\
\hline $\mathrm{ST}+\mathrm{FR}$ & 101 & 98 & 104 & 116 & 105 \\
\hline \multicolumn{6}{|c|}{ Neossolo Quartzarênico (NQ) } \\
\hline ST & $100(307)^{2}$ & $100(186)$ & $100(147)$ & $100(154)$ & $100(187)$ \\
\hline FA & $8(89)$ & $46(94)$ & $53(90)$ & 77 (115) & $44(44)$ \\
\hline FR & $36(180)$ & $70(111)$ & $68(91)$ & $96(130)$ & 66 (117) \\
\hline $\mathrm{ST}+\mathrm{FR}$ & 99 (302) & 91(174) & $90(127)$ & $98(131)$ & 95 (170) \\
\hline
\end{tabular}

${ }^{1} \mathrm{ST}=$ Superfosfato Triplo, FA = Fosfato de Araxá, FR = Fosfato Reativo de Arad; ${ }^{2}$ Percentagem de matéria seca da parte aérea produzida no NQ em relação à mesma fonte no LVdf.

(Tabela 4), comportamento expresso também pelos diferentes valores de IEA. O aumento da eficiência das fontes menos solúveis, FR e FA, com o tempo, observando os dados dos últimos cortes, corroboram informações de outros trabalhos (HOROWITZ \& MEURER, 2003), que indicam que os fosfatos naturais, notadamente os reativos, podem ser eficientes em suprir fósforo às culturas. Tal comportamento, especialmente no caso do FR, parece estar também relacionado a condições que interferem na dissolução dos fosfatos reativos, especificamente a elevada saturação de cálcio no ambiente de reação do produto, impedindo maior liberação inicial do P (KORNDORFER et al., 1999; NOVAIS \& SMYTH, 1999).

A diferença de produção de MSPA bem como do IEA entre os solos corrobora com as afirmações de Sousa et al. (2004) de que a eficiência da adubação fosfatada é influenciada pelo tipo de solo e pela fonte utilizada. No caso do tipo de solo, o tamponamento, relacionado ao teor de argila, modula a fração de $\mathrm{P}$ que vai permanecer disponível para a planta, razão pela qual nos solos argilosos a quantidade do nutriente deve ser maior. Este aspecto deve também ser considerado na avaliação econômica da atividade agrícola. 


\section{CONCLUSÕES}

Nesse estudo, em condições de casa de vegetação, a nutrição da braquiáira em $\mathrm{P}$ foi influenciada pelas fontes de fósforo. O solo NQ favoreceu um maior incremento na produção de matéria seca da parte aérea e das raízes da $B$. brizantha. $\mathrm{O}$ efeito das fontes na produção de matéria seca da parte aérea (MSPA) da braquiária ao final dos quatro cortes obedeceu a seguinte ordem decrescente: $\mathrm{FR}>\mathrm{ST}+\mathrm{FR}>\mathrm{ST}>\mathrm{FA}$, no LVdf e $\mathrm{ST}>\mathrm{ST}+\mathrm{FR}>\mathrm{FR}>\mathrm{FA}$ no NQ, respectivamente, comportamento que acompanhou o Índice de Eficiência Agronômica das fontes de fósforo.

\section{REFERÊNCIAS BIBLIOGRÁFICAS}

ARAÚJO, A. P.; ALMEIDA, D. L. Adubação verde associada a fosfato de rocha na cultura do milho. Pesquisa Agropecuária Brasileira, Brasília, v. 28, p. 245-51, 1993.

CORRÊA, L. de A. Níveis críticos de fósforo para o estabelecimento de gramíneas forrageiras em latossolo vermelho-amarelo álico: I. ensaio em casa de vegetação. Scientia Agricola, Piracicaba, v. 50, n. 1, p. 99-108, fev./ mar. 1993.

DELISTOIANOV, J.; MATTOS, H. B.; MONTEIRO, F. A. Aplicação de fontes de fósforo e gesso em uma pastagem consorciada estabelecida em um Latossolo VermelhoEscuro. Brazilian Industrial Animal, Nova Odessa, v. 49, n. 2, p. 83-90, jul./dez. 1992.

EMPRESA BRASILEIRA DE PESQUISA AGROPECUÁRIA. Embrapa Solos. Embrapa Informática Agropecuária. Manual de análises químicas de solos, plantas e fertilizantes. Brasília, DF, 1999. 370 p.

FAQUIN, V.; ROSSI, C.; CURI, N.; EVANGELISTA, A. R. Nutrição mineral em fósforo, cálcio e magnésio do Braquiarão em amostras de Latossolo dos Campos das Vertentes sob influência de calagem e fontes de fósforo. Revista Brasileira de Zootecnia, Viçosa, v. 26, n. 6, p. 10741082, 1997.

FREIRE, J. C.; RIBEIRO, M. A. V.; BAHIA, V. G.; LOPES, A. S.; AQUINO, L. H. Resposta do milho em casa de vegetação a níveis de água em solos da região de LavrasMG. Revista Brasileira de Ciências do Solo, Campinas, v. 4, n. 1, p. 5-8, 1980.

GOEDERT, W. J.; LOBATO, E. Avaliação agronômica de fosfatos em solo de cerrado. Revista Brasileira de Ciências do Solo, Campinas, v. 8, p. 97-102, 1984.
HOROWITZ, N.; MEURER, E. J. Eficiência agronômica de fosfatos naturais. In: SIMPÓSIO SOBRE FÓSFORO NA AGRICULTURA BRASILEIRA, 2003, Piracicaba. Anais... Piracicaba: Potafos/Anda, 2003. CD-ROM.

KORNDORFER, G. H.; LARA-CABEZAS, W. A.; HOROWITZ, N. Eficiência agronômica de fosfatos naturais reativos na cultura do milho. Scientia Agrícola, Piracicaba, v. 56, n. 2, p. 391-396, abr./jun. 1999.

MALAVOLTA, E.; VITTI, G. C.; OLIVEIRA, S. A. de (Eds.). Avaliação do estado nutricional das plantas: princípios e aplicações. Piracicaba: Associação Brasileira para pesquisa da Potassa e do Fosfato, 1997. 319 p.

MARSCHNER, H. Mineral nutrition of haigher plants. London: Academic, 1995. $889 \mathrm{p}$

MESQUITA, E. E.; PINTO, J. C.; FURTINI NETO, A. E.; SANTOS, I. P. A.; TAVARES, V. B. Teores críticos de fósforo em três solos para o estabelecimento de capim-Mombaça, capim-Marandu e capim-Andropogon em vasos. Revista Brasileira de Zootecnia, Viçosa, v. 33, n. 2, p. 290-301, 2004.

NAKAYAMA, L. H. I.; CACERES, N. T.; ALCARDE, J. C.; MALAVOLTA, E. Eficiência relativa de fontes de fósforo de diferentes solubilidades na cultura do arroz. Scientia Agricola, Piracicaba, v. 55, n. 2, p. 183-190, maio/ago. 1998.

NOVAIS, R. F.; SMYTH, T. J. Fósforo em solo e planta em condições tropicais. Viçosa: UFV/DPS, 1999. 399 p.

RAIJ, B. van; QUAGGIO, J. A.; CANTARELLA, H.; ABREU, C. A. Interpretação de resultados de análise de solo. In: RAIJ, B. van; CANTARELLA, H.; QUAGGIO, J. A.; FURLANI, A. M. C. (Eds.). Recomendações de adubação e calagem para o Estado de São Paulo. Campinas: Instituto Agronômico, 1996. p. 8-13.

RAO, I. M.; BORRERO, V.; RICAURTE, J.; GARCIA, R.; AYARZA, M. A. Adaptive attributes of tropical forage species to acid soils: 2. differences in shoot and root growth responses to varying phosphorus supply and soil type. Journal Plant Nutrition, Monticello, v. 19, n. 2, p. 323-352, 1996.

ROSSI, C.; FAQUIN, V.; CURI, N.; EVANGELISTA, A. R. Calagem e fontes de fósforo na produção do braquiarão e níveis críticos de fósforo em amostras de Latossolo dos Campos das Vertentes (MG). Revista Brasileira de Zootecnia, Viçosa, v. 26, n. 6, p. 1083-1089, 1997. 
SANTOS, H. Q.; FONSECA, D. M.; CANTARUTTI, R. B.; ALVAREZ, V. H.; NASCIMENTO JÚNIOR, D. Níveis críticos de fósforo no solo e na planta para gramíneas forrageiras tropicais, em diferentes idades. Revista Brasileira de Ciências do Solo, Campinas, v. 26, p. 173-182, 2002.

SANTOS, I. P. A.; PINTO, J. C.; SIQUEIRA, J. O.; MORAIS, A. R.; SANTOS, C. L. Influência do fósforo, micorriza e nitrogênio no conteúdo de minerais de Brachiaria brizantha e Arachis pintoi consorciados. Revista Brasileira de Zootecnia, Viçosa, v. 31, n. 2, p. 605-616, 2002.
SOUSA, D. M. G.; LOBATO, E.; REIN, T. Adubação com fósforo. In: SOUSA, D. M. G.; LOBATO, E. (Eds.). Cerrado: correção do solo e adubação. 2. ed. Brasília, DF: Embrapa Informação Tecnológica, 2004. p. 147-168.

YOST, R. S.; KAMPRATH, E. J.; NADERMAN, G. C.; LOBATO, E. Residual effects of phosphorus adsorving Oxisol of Central Brazil. Soil Science Society America Journal, Madison, v. 45, p. 540-543, 1981. 